Fourth International Conference on Sustainable Construction Materials and Technologies

http://www.claisse.info/Proceedings.htm

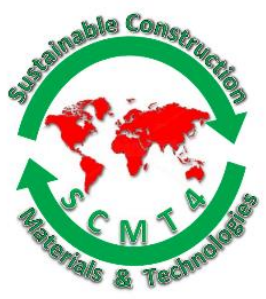

SCMT4

Las Vegas, USA, August 7-11, 2016

\title{
Utilization of Post-Consumer Plastics in Sustainable Concrete: An Overview
}

\author{
Rakesh Kumar $^{1 *}$ and Tarun R. Naik ${ }^{2}$ \\ ${ }^{1}$ Principal Scientist, CSIR-Central Road Research Institute, Delhi-Mathura Road, New Delhi, India. \\ Email: 〈rakeshkumar.crri@nic.in>. \\ ${ }^{2}$ Emeritus Professor of Civil Engineering, formerly Research Professor and Academic Program Director, \\ UWM Center for By-Products Utilization, University of Wisconsin-Milwaukee, USA. \\ Email: 〈tarun@uwm.edu>.
}

\begin{abstract}
The amount of plastics in municipal solid waste (MSW) in the USA has increased from 1\% in 1962 to $13 \%$ in 2013. It constitutes about 33 million tons of the total MSW generated; i.e., about 255 million tons in 2013. The recycling rate for different types of plastic varies. However, the overall plastics-recycling rate was about $3.5 \%$ by weight or $9.2 \%$ by the volume of the MSW generated. The most widely recycled postconsumer plastic is polyethylene terephthalate (PET), commonly found in soft drink bottles; followed by high-density polyethylene (HDPE), found in milk jugs and base cups of soft drink bottles. The recycling rate of PET bottles and jars was highest, about $31 \%$, followed by HDPE bottles at about $28 \%$. Recycled plastic is generally used to produce resin, fibers, and aggregates/fillers to be used in concrete for manufacturing of specific products. Several research studies have been carried out to demonstrate the possibility of using such recycled products derived from post-consumer plastic, especially in the manufacture of concrete with the help of appropriate technology for imparting benefits to the concrete. This paper presents an overview of research findings reported from the studies carried out on the roles of materials derived from recycled post-consumer plastics in the manufacture of sustainable concrete.
\end{abstract}

\section{INTRODUCTION}

The three main challenges in the realization of sustainable development includes: ensuring availability of natural resources for future generation, control of exceeding limits of biosphere to recycle and absorb residues and pollutions, and reduction of poverty worldwide. Therefore, the ideology of developing sustainable concrete includes resource conservation, reduction in carbon footprint of concrete including reduction in the generation of pollutants, minimization of waste generation, and recycling of industrial and agricultural by-product materials and post-consumer materials, in the manufacture of concrete. Further, the need for developing a sustainable concrete is increasing day-by-day. Manufacturing of sustainable concrete requires judicious use of natural resources and lower environmental impact in comparison to the conventional concrete. This is generally achieved through reduced mining of natural resources required for 
manufacture of the concrete. With a desire to develop sustainable infrastructures, resource conservation, and contribution to the reduction in the causes of global climate change by reducing carbon footprint of concrete, concrete-making materials, and reduction in pollutants associated with them, and through environmentally-friendly techniques of concrete manufacturing by using recyclable materials should be encouraged. The current concrete construction practice is considered unsustainable as it consumes huge quantity of natural resources such as stone, sand, and water every year. Each of the basic ingredients of concrete has some adverse environmental impact; and, therefore, they give rise to different sustainability issues. The portland cement-based concrete is also a major consumer of natural resources - rock, minerals, potable water, and fossil fuel, which is increasing year-by-year resulting in a faster rate of depletion of such natural resources needed for the manufacture of both the portland cement and concrete. The production of portland cement contributes to global climate change due to the release of GHGs (green house gases) principally $\mathrm{CO}_{2}$ in the Earth's atmosphere [Naik and Kumar 2012]. Manufacturing of concrete and its products have a significant impact on the environment as the production of concrete releases GHGs, which includes the emissions from the mining of raw materials, transportation, construction, maintenance, demolition, and disposal or recycling processes at the end of life of the infrastructures constructed with concrete. In the light of limited natural resources and adverse impacts on the global climate change, the concrete industry must play a vital role by encouraging the technology for the development of sustainable concrete for prolonged service life, conservation of natural resources, reduction in energy required, and minimizing GHGs emission from its manufacturing and transportation of concrete-making materials and products. The success of such technology mainly depends on local conditions, norms, and practices. Understanding of the environmental issues in the manufacturing activities of concrete and its products are the main driving forces for the advent of sustainable concrete.

Sustainable concrete is an intelligent solution that mitigates adverse effects of its manufacturing by consuming less energy and less natural resources (for example, recycling of suitable by-products from industry and post-consumer products, agricultural wastes, municipal waste, and other similar materials) in its manufacturing. Although the technical as well as economical benefits of the inclusion of certain industrial by-products in concrete have been documented from past several decades, the total advantages derived from such uses allow these industrial by-product materials to be considered as a means to reduce the cost of the concrete and, also, be considered as essential ingredients for the manufacturing of a sustainable concrete. Similarly, suitable post-consumer materials such as post-consumer waste plastics can be used for the purpose of reduction of the carbon footprint and conservation of the natural resources required for sustainable concrete manufacturing.

The global use of plastics is increasing everyday; and, substantial amount of plastics ends up in landfills as a post-consumer waste. In 2013, post-consumer plastics made up almost 33 million tons of the total MSW (municipal solid wastes) generated; i.e., 254 million tons in the United States [USEPA 2015]. The amount of plastic in MSW has increased from 1\% in 1962 to 13\% in 2013. The plastic waste is a serious environmental threat as it pollutes soil, air, and water and consists of several toxic chemicals. The threat of plastic waste is increasing because of its ever-increasing consumption across the globe. Incineration of plastic releases a variety of poisonous chemicals into the atmosphere. Recycling of plastic waste for the production of new plastic -based products after processing degrades its quality. Alternatively, recycling of waste plastic for the manufacture of materials such as cement-composites; i.e., cement-based products seems to be one of the best economical and environmental-friendly options for utilization of post-consumer waste plastic. Plastics can be divided in to two major categories: thermosets and thermoplastics. Thermoplastics can easily be shaped and molded into products such as milk jugs, soda bottles, carpet fibers, and many other similar products. There are seven types of plastics: (1) polyethylene terephthalate (PET), commonly found in soft drink bottles is the number one recycled resin; (2) high-density polyethylene (HDPE), the second most commonly recycled resin, is found in milk jugs and base cups of soft drink bottles; (3) polystyrene (PS), commonly used in egg cartons, plates, cups, and packaging "peanuts"; (4) low-density polyethylene (LDPE), generally found as plastic grocery bags and trash bags; (5) polypropylene (PP), 
generally used in hard-casings of luggage and battery castings; (6) poly-vinyl chloride (PVC) used in flooring, piping, wiring, and other similar uses; and, (7) linear low-density polyethylene (LLDPE) [USEPA 2014]. The recycling rate for different types of plastic varies, resulting in an overall plastics recycling rate (in 2013) of only $9.2 \%$ by volume or about $3.5 \%$ by weight. About $29 \%$ of HDPE bottles and 31 percent of PET bottles and jars were recycled in 2013 in the USA [USEPA 2015]. The most widely recycled postconsumer plastic waste is polyethylene terephthalate (PET) followed by high-density polyethylene (HDPE). In order to reduce the disposal problems of large amount of plastic waste, recycling it in concrete industry is considered as one of the most suitable and feasible options. The most commonly recycled post-consumed plastic waste in cement-based products, i.e. cement mortar and concrete, is PET bottles and HDPE for the purpose as aggregates, a filler, a fiber, or resin in the preparation of concrete. Several research studies have demonstrated a possibility for using recycled products derived from post-consumer plastic in the manufacture of concrete with the help of appropriate technology for imparting benefits to the concrete. This paper presents an over-view of the extensive research findings reported from the studies carried out on the roles of materials derived from recycled post-consumer plastics in the manufacture of sustainable concrete.

\section{RECYCLING OF POST-CONSUMER PLASTICS IN CEMENT CONCRETE}

Compared to other post-consumer materials such as glass, metals, tires, etc., plastic polymers require greater processing to be recycled. It is difficult and uneconomical to recycle all different types of plastic wastes. The most widely recycled post-consumer plastic waste is polyethylene terephthalate (PET) [Mahdi et al. 2010, 2013; Saikia and de Brito J. 2014; Akcaozoglu et al. 2010; Choi et al. 2005, 2009; Kim et al. 2010; Marzouk et al. 2007] followed by the high-density polyethylene (HDPE) [Naik et al. 1994, 1996; ]. Besides PET and HDPE plastics, attempts have been made to use poly vinyl chloride (PVC) pipe [Kou et al. 2009], thermosetting waste plastic [Gavela et al. 2013] shredded and recycled plastic waste [Soroushian et al. 2003; Ismail and Al-Hashmi 2008; ], expanded polystyrene foam (EPS) [Kan and Demirboga 2009] glass reinforced plastic (GRP) [Asokan et al. 2010; Bajracharya et al. 2014], polyurethane foam [Fraj et al. 2010] as an aggregate, a filler in the manufacture of concrete. Recycled plastic is generally used to produce resin, fibres, and aggregate to be used in concrete for manufacturing of specific products. Typical PET bottle flakes (Figure 1) and shredded bottle plastic strips (Figure 2) are shown below which could be used in the manufacture of concrete after further processing.

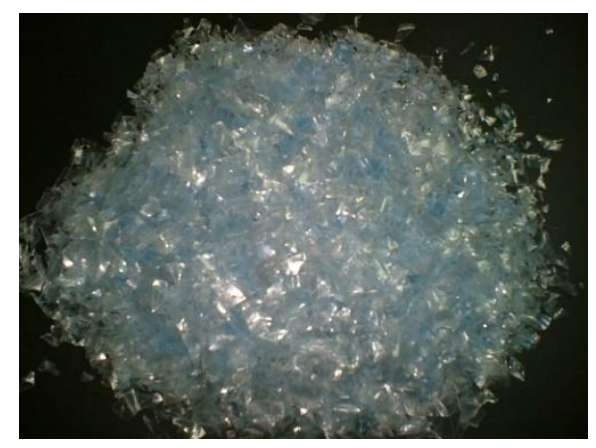

Figure 1. PET Bottle Flakes

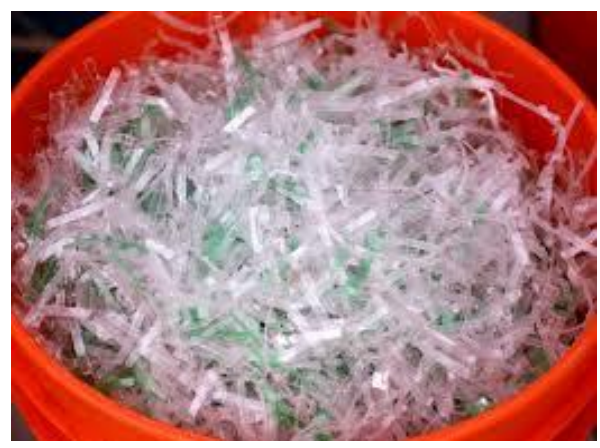

Figure 2. Bottle Plastic Strips

Applications of recycled-plastics in concrete. In the past, many attempts have been made to use recycled post-consumer plastics derivatives such as resin as an alternate binder, aggregates (as an replacement of natural aggregate that is fine as well as coarse), and fibres (filler) in portland cement concrete.

Resin reclaimed from PET. Rebeiz et al. 1993 and 1994 carried out study for the use of resin reclaimed from PET derived from soda bottles in the manufacturing of polymer concrete system. For this purpose, 
the PET material was processed to produce a liquid resin using facilities available at a commercial company. This process is not available for other types of plastic and is not considered economically feasible yet. For such investigations reported, unsaturated polyester resins were obtained from several commercial sources. Each contained a particular percentage of recycled PET. The amount of recycled PET varied between $15 \%$ and $40 \%$. These resins were pre-polymers with high viscosities (100 to $1890 \mathrm{cps}$ ). Styrene was added to reduce the viscosity of the resins. Further, appropriate initiators and promoters were then added to the resins immediately prior to the mixing with concrete aggregates in order to initiate and accelerate polymerization (curing or hardening of the resin to a solid plastic state). For manufacture of polymer concrete (PC), the resin and aggregate were mixed in a conventional concrete mixer for approximately three minutes and then the specimens were cast, vibrated, and allowed to cure at the room temperature for 3 to 9 days prior to testing. In general, the researchers concluded that the inclusion of recycled PET did not have detrimental effects on the polymer concrete.

Plastic aggregates. In general, aggregate derived from post-consumer plastic waste either from grinding or shredded in flakes or in pellet form collected from plastic waste treatment plants/plastic manufacturing plans or prepared in laboratory, has been reported. Some researchers [Naik et al. 1994, 1996; Akcaozoglu et al. 2010; Marzouk et al. 2007] have adopted washing of the aggregate to remove impurities present in the plastic aggregates. In some cases, the plastic samples were subjected to chemical treatment, bleach, and bleach plus $\mathrm{NaOH}$ (alkaline bleach) Table 1. Some plastic samples were subjected to water pre-treatment in order to separate impurities (nonplastic particles) from plastic particles and for a better adhesion with matrix. This treatment also caused dissolution of detergent and surfactant from polymer surfaces. In some study [Choi et al. 2009; Ghernouti et al., 2015] special method for plastic aggregate preparation was adopted.

Table 1. Different Treatment of Plastic Aggregate before using in Concrete Mixtures [Naik et al. 1994]

\begin{tabular}{|l|c|c|c|c|}
\hline Mix. No. & P1 & P2 & P3 & P4 \\
\hline Plastic, lbs & 7 & 7 & 7 & 7 \\
\hline Water & Yes & No & No & Yes \\
\hline $5 \%$ Hypochlorite Solution, L & 0 & 15 & 15 & 0 \\
\hline $\begin{array}{l}5 \% \text { Hypochlorite Bleach + } \\
\text { \% Sodium Hydroxide }(\mathrm{NaOH}), \mathrm{lb}\end{array}$ & 0 & 0 & 1.32 & 0 \\
\hline Total Soak Time & $16 \mathrm{hrs} *$ & 7 days** & 6 days** & $23 \mathrm{hrs} *$ \\
\hline Drying Time & $1 \mathrm{hr}$. & $1 \mathrm{hr}$. & $12 \mathrm{hrs}$. & $1 \mathrm{hr}$. \\
\hline
\end{tabular}

* The degree of cleanness was about the same in both the cases.

** The soaking time between 5-7 days have been found to have the same effect.

In that method plastic aggregate i.e. cutting of waste PET bottle was mixed with powdered river sand and blast furnace slag and heated at $250^{\circ} \mathrm{C}$. After air-cooling the mixtures, the aggregates so prepared were sieved with 150 micron sieve. 


\section{EFFECT OF PLASTIC AGGREGATES ON THE FRESH PROPERTIES OF CONCRETE}

Workability slump, unit weight/fresh density and air content. The workability or consistency of fresh concrete mixtures is generally measured in the term of slump. In most of the studies concerned with the use of plastic aggregate in concrete, the influences of the addition of plastic aggregate as a replacement of natural aggregate, on fresh properties of concrete such as slump and density have been investigated (Table 2). Generally, a reduction in the value of slump of concrete with increasing content of plastic aggregate has been reported in several studies [Naik et al. 1994; Frigione 2010; Marzouk et al. 2007;]. The irregular sharp edges and angular particle size of the plastic aggregate was held responsible for the lower value of slump of the concrete mixture containing plastic aggregate. Contrary to this, there are several studies [Choi et al. 2009; Yang et al 2015; Ghernouti et al. 2015] where an increase in the slump value of concrete mixtures after incorporation of plastic aggregated are reported. The non-absortive characteristics of the plastic aggregate, slippery surface texture and spherical shape of the plastic aggregate were held responsible for the increase in the value of slump of the mixtures. Therefore, the increase or decrease in the slump value of concrete mixture containing plastic aggregate with respect to conventional concrete mixture mainly depends on the particle shape, texture, and size of the plastic aggregate.

Irrespective of the type, size, and level of substitutions, the incorporation of plastic aggregate results in a lower density of concrete which is mainly due to lower specific weight of the plastic aggregate. The unit weight of concrete containing post-consumer plastic is lower than the conventional concrete. Therefore, it is suitable for the manufacture of light weight concrete as well as structural concrete of lower density than conventional concrete.

There is hardly any study available showing the influence of the addition of waste plastic aggregate on the air-content of a concrete mixture.

Table 2. Fresh Properties of Concrete as Reported in the Literature

\begin{tabular}{|c|c|c|}
\hline Reference & Slump & Fresh density \\
\hline Naik et al. 1994, 1996 & $\sqrt{ }$ & $\sqrt{ }$ \\
\hline Ismail and Al-Hasmi 2008 & $\sqrt{ }$ & $\sqrt{ }$ \\
\hline Marzouk et al. 2007 & $\sqrt{ }$ & $\sqrt{ }$ \\
\hline Frigione 2010 & $\sqrt{ }$ & $\sqrt{ }$ \\
\hline Kan and Demirboga 2009 & $\sqrt{ }$ & $\sqrt{ }$ \\
\hline Fraj et al. 2010 & $\sqrt{ }$ & $\sqrt{ }$ \\
\hline Choi et al. 2005, 2009 & $\sqrt{ }$ & \\
\hline Ghernouti et al. 2015 & $\sqrt{ }$ & \\
\hline Yang et al. 2015 & & \\
\hline Saikia and de Brito J. 2014; & & \\
\hline
\end{tabular}

Hardened Properties of Concrete with Plastic Aggregate. The most commonly reported hardened state properties of concrete containing plastic aggregate derived from post-consumer plastic are compressive strength, splitting tensile strength, and flexural strength. In almost all studies [Naik et al. 1994; Akcaozoglu 
et al. 2010; Marzouk et al. 2007; Choi et al. 2009; Ghernouti et al., 2015; Mahdi et al. 2010, 2013; Saikia and de Brito J. 2014; Akcaozoglu et al. 2010; Choi et al. 2005, 2009; Kim et al. 2010; Marzouk et al. 2007] related to use of plastic aggregate in concrete, it is found that the incorporation of plastic aggregate as a replacement of natural aggregate decreases the compressive strength, splitting tensile strength and flexural strength of concrete and cement mortar. The reduction in compressive and splitting tensile strength is similar. However, in the case of flexural behaviour, the reduction in flexural strength is not as much as in compressive and splitting tensile strength of concrete containing plastic aggregate. The reasons for the reduction in strengths of concrete with plastic aggregate includes a lower bond strength between the surface of plastic aggregates and cementitious matrix; the hydrophobic nature of plastic aggregate which could cease cement hydration reaction by restricting water movement; type of failure, loss of workability etc. One noticeably different behavior of cylinders used for splitting tensile strength includes non splitting of cylinder into two parts after determination of tensile strength for concrete mixtures containing flaky-shaped plastic aggregate. The reason for this behaviour of cylinders is attributed to bridging action of flaky-shaped plastic aggregate [Saikia and de Brito J. 2014].

Use of post-consumer plastics as a flexible particulate filler in concrete should improve its fracture toughness. However, due to the absence of a chemical bond between plastic filler and cementitious matrix, the potential increase in toughness was generally not achieved. To solve this problem, Naik et al 1994, introduced chemical bond between plastic particles and cementitious matrix using chemical treatments. The plastic particles were added to the concrete in the range of 0 to $5 \%$ of the total mixture by weight. In order to increase the bond between the plastic particles and the concrete matrix, the plastic particles were subjected to three chemical treatments (water, bleach, and bleach plus $\mathrm{NaOH}$ ). The compressive strengths of the concrete with and without plastic particles were evaluated. All concrete mixtures developed lower compressive strength than the reference concrete; however, the mixture containing plastic treated with bleach plus $\mathrm{NaOH}$ performed the best, followed by the water-treated plastic sample. The study concluded that concrete containing plastic (ranging $0 \%$ to $2 \%$ by the total weight of the concrete) treated with water showed that $0.5 \%$ of plastic could be used in concrete without compromising the compressive strength. Beyond $0.5 \%$ addition of plastic particles by the weight of the concrete, concrete strength decreased. The authors recommended that plastic should be processed to obtain high aspect ratios for improving the performance of the plastic filler due to its increased bond area and its load transfer capability. They demonstrated that the chemical treatment, alkaline bleach treatment (bleach plus $\mathrm{NaOH}$ ), on plastic had a noticeable effect on performance with respect to compressive strength and tensile strength development of the concrete with such plastics.

The mechanical properties such as compressive strength, modulus of elasticity, and tensile strength of concrete containing plastic aggregate derived from post-consumer plastic decreased with increase in the plastic aggregate content. However, better structural efficiency (lightweight concrete) and toughness are some important beneficial properties that make the use of recycled products derived from post-consumer plastic as quite beneficial. Such uses include fibre for the manufacturing of various precast products such as sewer pipes, underground vaults, power line transmission poles, median barriers of roads, and other similar products. Building bricks containing granulated post-consumer waste plastics as the aggregate in concrete has been shown in Figure 3[http://inhabitat.com/plastic-concrete-repurposes-landfill-waste-intobuilding-bricks]. As a fine aggregate PET post-consumer plastics may be used for the development of lightweight aggregate concrete; however, the compressive strength of such concrete may reduce by $5 \%$ to $30 \%$ depending upon the quantity of PET in the concrete mixture. The structural efficiency i.e. compressive strength/density of such concrete is higher than conventional concrete [Marzouk et al. 2007].

Abrasion Resistance. Very little information is available on the abrasion resistance of concrete containing plastic aggregate. Soroushian et al. 2003, reported a reduction in abrasion resistance of concrete containing plastic waste fibre. But Saikia and de Brito 2012 reported an improvement in abrasion resistance of concrete containing PET aggregate. 


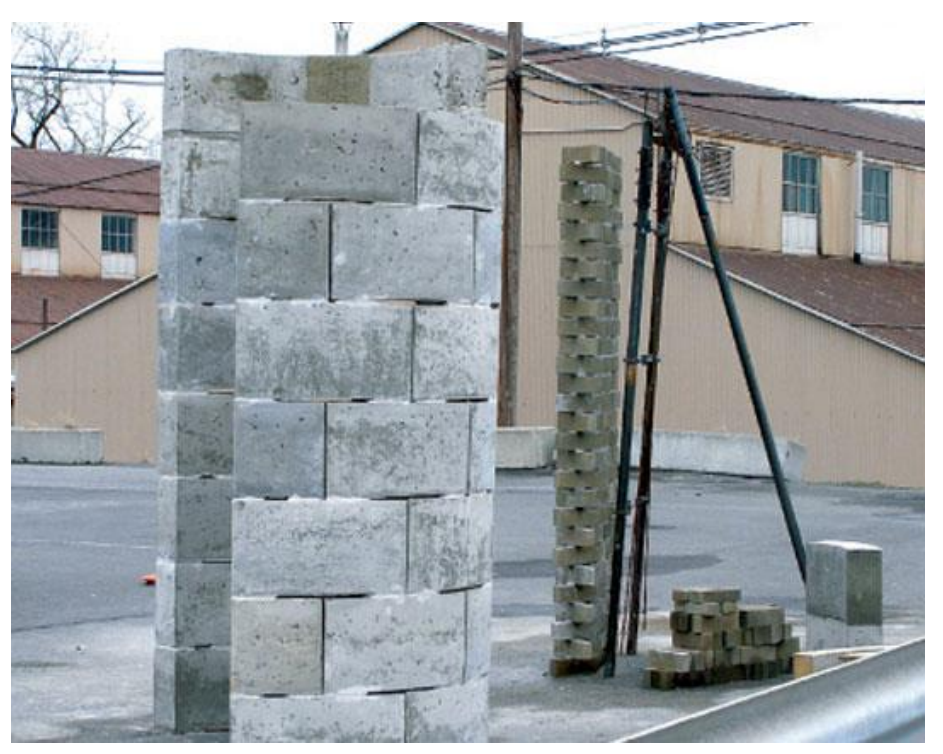

Figure 3. Building Bricks Containing Granulated Post Consumer Waste Plastics

[http://inhabitat.com/plastic-concrete-repurposes-landfill-waste-into-building-bricks]

\section{DURABILITY OF CONCRETE WITH PLASTIC AGGREGATE}

In comparison to the available information on mechanical properties of concrete with plastic aggregate, there is very limited information available on durability factors such as water absorption and sorptivity, shrinkage, carbonation resistance, chloride ion penetration and resistance against freezing and thawing etc., for concrete containing plastic aggregate.

\section{CONCLUSION}

The study presented in this paper shows that there is an excellent potential for the utilization of postconsumer plastics in the manufacturing of sustainable concretes in several forms including as fine aggregate, coarse aggregate, binder, and filler. Based on the study presented here, the following conclusions are drawn:

1. Aggregate derived from the post-consumer plastics, with or without surface treatment, can be used as a partial replacement of aggregates to be used in the manufacture of a sustainable concrete.

2. Among all post-consumer plastics, PET and HDPE are the most widely recycled plastics for use in manufacturing of ingredients for a concrete; i.e. aggregate, binder, and even as an additional ingredient as fibers for imparting desirable benefits to the concrete.

3. Downgraded mechanical properties of concrete containing used post-consumer plastics can be brought to the acceptable level by the use of currently available knowledge.

\section{ACKNOWLEDGEMENT}

The UWM Center for By-Products Utilization was established in 1988 with a generous grant from the Dairyland Power Cooperative, La Crosse, Wisconsin; Madison Gas and Electric Company, Madison, Wisconsin.; National Minerals Corporation, St. Paul, Minnesota; Northern States Power Company, Eau Claire, Wisconsin.; We Energies, Milwaukee, Wisconsin.; Wisconsin Power and Light Company, Madison, Wisconsin; and, Wisconsin Public Service Corporation, Green Bay, Wisconsin. Their financial support and additional grant and support from Manitowoc Public Utilities, Manitowoc, Wisconsin, are gratefully acknowledged 


\section{REFERENCES}

Akcaozoglu S., Atis C. D., and Akcaozoglu K. (2010). "An Investigation on the Use of Shredded PET Waste Bottles as Aggregate in Lightweight Concrete.” Waste Management, 32(2), 285-290.

Al-Manaseer A. A., and Dalal T. R. (1997). "Concrete Containing Plastic Aggregates", Concrete International, 19(1), 47-52.

Asokan, P., Osmani, M., and Price, A. D. F. (2010). "Improvement of the Mechanical Properties of Glass Fibre Reinforced Plastic Waste Powder Filled Concrete." Construction and Building Materials, 24(4), 488-460.

Bajracharya, R. M., Manalo, A. C., Karunasena, W., and Lau, K-t (2014). “An Overview of Mechanical Properties and Durability of Glass-Fiber Reinforced Mixed Plastic Waste Composites." Materials and Design, 62, 98-112.

Choi Y. W., Moon D. J., Chung J. S., and Cho S. K. (2005). "Effect of PET Waste Bottles Aggregate on the Properties of Concrete, Cement Concrete Research, 35 (4), 776-781.

Choi Y. W., Moon D. J., Kim Y. J., and Lachemi M. (2009). "Characteristics of Mortar and Concrete Containing Fine Aggregate Manufactured From Recycled Waste Polyethylene Terephthalate Bottles", Construction and Building Materials, 23(8), 2829-2835.

Correia J. R., Lima J. S., and Brito J. De. (2014). "Post-Fire Mechanical Performance of Concrete Made With Selected Plastic Waste Aggregates", Cement and Concrete Composites, 53, 187-199.

Ferreira, L., Brito, J-de., and Saikia, N. (2012). "Influence of Curing Conditions on the Mechanical Performance of Concrete Containing Recycled Plastic Aggregate, Construction and Building Materials, $36,196-204$.

Fraj A. B., Kismi M., and Mounanga P. (2010). "Valorization of Coarse Rigid Polyurethane Foam Waste in Lightweight Aggregate Concrete", Construction and Building Materials, 24(6), 1069-1069.

Frigione, M. (2010). "Recycling of PET Bottles as Fine Aggregate in Concrete.” Waste Management, 30(6), 1101-1106.

Gavela, S., Ntziouni, A., Rakanta, E., Kouloumbi, N., and Kasselouri-R, V. (2013). "Corrosion Behaviour of Steel Re-Bars in Reinforced-Concrete Containing Thermoplastic Wastes as Aggregates, Construction and Building Materials, 41, 419-426.

Ghernouti Youcef, Rabehi Bahia, Safi Brahim and Chaid Rabah. (2015). "Use of Recycled Plastic Bag Waste in The Concrete", Journal of International Scientific Publication: Materials, Methods and Technologies, <http://www.scientific-publications.net>.

http://inhabitat.com/plastic-concrete-repurposes-landfill-waste-into-building-bricks (10 Dec 2015).

Ismail, Z. Z., and Al-Hasmi, E. A. (2008). "Use of Plastic Waste in Concrete Mixture as Aggregate Replacement.” Waste Management, 28(11), 2041-2047.

Kan A., and Demirboga R. (2009). "A Novel Material for Lightweight Concrete Production”, Cement and Concrete Composites, 31(7), 489-495.

Kim S. B., Yi N. H., Kim H. Y., Kim J. H. J., and Song Y. C. (2010). Material and Structure Performance Evaluation of Recycled PET Fibre Reinforced Concrete", Cement and Concrete Composites, 32(3), 23240. 
Kou S.C., Lee G, Poon C. S., and Lai W. L. (2009). "Properties of Lightweight Aggregate Concrete Prepared with PVC Granules Derived from Scraped PVC Pipes", Waste Management, 29(2), 621-628.

Mahdi, F., Abbas, H., and Khan, A. A. (2013). "Flexural, Shear and Bond Strength of Polymer Concrete Utilizing Recycled Resin obtained from Post-Consumer PET Bottles, Construction and Building Materials, 24(5), 798-811.

Mahdi, F., Abbas, H., and Khan, A. A. (2010). "Strength Characteristics of Polymer Mortar and Concrete Using Different Compositions of Resins Derived from Post-Consumer PET Bottles, Construction and Building Materials, 24 (1), 25-36.

Marzouk, O. Y., Dheilly, R. M., and Queneudec, M. (2007). "Valorisation of Post-Consumer Waste Plastic in Cementitious Concrete Composites, Waste Management, 27(2), 310-318.

Mounanga P., Gbongbon W., Poullain P., and Turcy P. (2008). "Proportioning and Characterization of Lightweight Concrete Mixtures Made with Rigid Polyurethane Foam Wastes", Cement and Concrete Composites, 30(9), 806-814.

Naik, T. R., and Kumar, R. (2012). Global Warming and Cement-Based Materials, http://www.amazon.com (5 Dec. 2015).

Naik, T. R., Singh, S. S., and Brodersen, B. S. (1994). "Construction materials Containing Polymeric Substances and Used Plastics", A CBU Technical Report, Center for By-Products Utilization, University of Wisconsin-Milwaukee, U.S.A.

Naik, T.R., Singh, S. S., Huber, C. O., and Brodersen, B. S. (1996). "Use of Post-Consumer Waste Plastic in Cement-Based Composites, Cement and Concrete Research, 26(10), 1482-1489.

Ochi, T., Okubos, S., and Fukui, K. (2007). "Development of Recycled PET Fibre \& its Application as Concrete-Reinforcing Fibre, Cement and Concrete Composites, 29(6), 448-455.

Panyakapo P., Panyakapo M. (2008). "Reuse of Thermosetting Plastic Waste for Lightweight Concrete", Waste Management, 28(9), 1581-1588.

Rebiez, K. S., Fowler, D. W., and Paul, D. R. (1994). "Mechanical Properties of Polymer Concrete Systems Made with Recycled Plastic, ACI Materials Journal, 91(1), 40-45.

Rebiez, K. S., Fowler, D. W., and Paul, D. R. (1993). "Recycling Plastics in Polymer Concrete for Construction Applications, ASCE Journal of Materials in Civil Engineering, 5(2), 237-248.

Saikia, N., and Brito, J-de. (2012). "Use of Plastic Waste as Aggregate in Cement Mortar and Concrete Preparation: A Review, Construction and Building Materials, 34, 385-401.

Soroushian, P., Plasencia J., and Ravanbakhsh S. (2003). "Assessment of Reinforcing Effects of Recycled Plastic and Paper in Concrete", ACI Materials Journal, 100(3), 203-207.

USEPA (2015). <http://www.epa.gov/osw/conserve/materials/plastics.htm>, (23 July. 2015).

USEPA (2014). 〈http://www.epa.gov/recycle/how-do-i-recycle-common-recyclables\#plastic> (1 Dec. 2015).

Yesilata B., Isiker Y., and Turgut P. (2009)., "Thermal Insulation Enhancement in Concretes by Adding PET Waste and Rubber Pieces", Construction and Building Materials, 23, 1878-1882. 